\title{
IDENTIDADE E DIFERENÇA DE QUEM PINTA O CORPO \\ PARA A GUERRA OU PARA A FESTA: \\ A TRAJETORIA DA POÉTICA DE RESISTÊNCIA \\ DO GRUPO URUCUM (200I-2005)'
}

\section{Arthur Leandro \\ ICA-UFPA}

\author{
Orlando, é daqui pro güera...
}

Minha análise segue esse raciocínio de que o circuito de mercado "matou" socialmente a produção de arte, e daí eu me aproveito principalmente do güera, diferenciando-o vivo do morto (só é carne viva no corpo do animal, sóquera é o bife na tua panela) para pensar na possibilidade do güera no sentido inverso - pegar o circuito morto e reviver a nossa produção como uma produção socialmente periférica feita como um hiato conceitual da arte, um güera, mas que mesmo que não seja reconhecida como "arte" ainda assim estará viva na sociedade.

\section{PREÂMBULO}

Minha intenção é analisar a produção de trabalhos coletivos do Grupo Urucum² no período de 2001 a 2005, período em que participo ativamente do grupo, perguntando se pode chamá-la de uma produção de arte contemporânea, e mais, qual a necessidade de caracterizá-la assim.

São nove as ações do universo dos trabalhos do grupo que tomo como objeto: 1) "Os catadores de orvalho esperando a felicidade chegar" (Macapá - 2001); 2) "Desculpem o transtorno - estamos em obras" (Rio de Janeiro - 2002); 3) "projeto rejeitados" (2002/03); 4) "Mensagens Vazias" (Macapá - 2002/03); 5) "Divisória-imaginária" (Macapá - 2003); 6) "Bicicletas elétricas" (Nova lorque - 2003/04); 7) "Lotação de paus mandados" (Macapá - 2004); 8) "Corpo Fechado" (Rio de Janeiro - 2004); 9) "Concerto de Roqueroques" (Macapá/Kassel-2005).

Estas ações coletivas do grupo são realizadas a partir de motivações baseadas na realidade local, mesclando questões poéticas com a tensão social, a vivência na cidade de Macapá, as relações entre a cultura amazônica e a globalização, ou tensionando a relação entre artistas e instituições, mesmo quando são ações realizadas para participação em eventos em instituições culturais.
A participação do Grupo em eventos de instituições culturais acontece pela conexão em rede de comunicação com outros artistas, como no "Desculpem o Transtorno - estamos em obras", realizado no Palácio Gustavo Capanema - sede da FUNARTE no Rio de Janeiro; do "projeto rejeitados", pensado para o Museu de Arte Moderna da Bahia e nunca realizado; e do "Bicicletas elétricas", realizado no American Society, em Nova Iorque ${ }^{3}$; e a partir de então por convite direto, como no "Mensagens Vazias"4, "Corpo Fechado", realizado na praia de Ipanema no Rio de Janeiro5; e "Concerto de Roque-roques", realizado simultaneamente na feira maluca em Macapá e no Kunsthalle Museum Fridericianum, em Kassel - Alemanha. Apesar de em Macapá não haver espaços de exposição integrados ao circuito oficial da arte brasileira, de alguma forma os membros do grupo puderam tomar contato e se relacionar diretamente com o universo institucional impositivo que legitima e controla a produção artística brasileira, assumindo o trânsito institucional sem integrar-se totalmente a ele, numa postura crítica que tenta não ser submissa ao poder.

O meu interesse por essa parcela da produção do Grupo Urucum dá-se pelo uso de estratégias diferenciadas do procedimento tradicional 
e secularizado de legitimação artística, pela experimentação poética de relação direta com a sociedade e realização de propostas em espaços urbanos - sem a mediação institucional, pela participação crítica quando em eventos no interior das instituições culturais, ou pela participação em redes de comunicação e ações conjuntas com outros artistas e coletivos artísticos. O que pressuponho é que o uso dessas estratégias caracteriza as ações do coletivo como atividades de resistência política e cultural.

Na minha proposição e no meu texto eu falo na primeira pessoa, alternando o posicionamento do singular com o plural, mas em todo caso declarando a proximidade com o objeto de pesquisa. E não havendo o distanciamento para com o objeto proposto, a pesquisa torna-se uma pesquisa participante, eu também faço parte do objeto ${ }^{6}$ e não separo o artista do teórico, do ativista. Mesma mistura, ou alternância de posições, com que caracterizo minha participação nas ações do grupo Urucum.

\section{IDENTIDADES, DIFERENÇAS E ESTRATÉGIAS DIANTE DO SISTEMA}

O exemplo dos projetos modernistas - de uma arte "desinfetada" - que acompanham a racionalização imposta pela modernização acaba por gerar códigos artísticos que impossibilitam, cada vez mais, o acesso do homem comum às produções simbólicas consideradas legítimas. Estes projetos implantados na América Latina são denunciados por Néstor García Canclini como um simulacro urdido pelas elites e pelos aparelhos estatais, sobretudo os que se ocupam da arte e da cultura, mas que por isso mesmo os torna irrepresentativos e inverossímeis da cultura viva e híbrida que se manifesta paralela ao crescimento da vida urbana. As elites - que pretendiam manter sua distinção em relação às outras classes através do monopólio dos códigos estéticos considerados superiores quando comparados aos populares ou massivos - não consideravam as desigualdades em seus projetos modernos, sendo estes sempre excludentes da maioria da população, à qual restam as opções do folclore popular ou das produções massivas geradas pela indústria cultural (CANCLINI, 2001).

No início do século XIX, a história luso-brasileira foi marcada por dois grandes acontecimentos: a invasão de Portugal pelo exército francês, e a transferência da família real e da Corte portuguesa para o Brasil. Consequência direta da invasão francesa, a chegada da Corte lusitana, em 1808, representou para o Brasil um momento de profunda mudançainstitucionale cultural. Dianteda nova condição de sede do governo metropolitano, a colônia americana passou por uma importante reestruturação político-administrativa ${ }^{7}$, dando início à construção do aparato burocrático-estatal necessário para atender as novas exigências de sede do governo português. Como parte da (re) estruturação administrativa e política, em 1816, D. Joao VI contrata um grupo de artistas franceses encarregados de implantar a Academia de Belas Artes $^{8}$, cujo objetivo era o ensino e propagação das artes e ofícios artísticos, segundo os modelos vigentes na Europa?.

A missão francesa oficializa a arte produzida segundo o gosto do governante e relega a planos inferiores todas as demais produções artísticas, fruto da diversidade cultural brasileira. A história registra esse período como de grande efervescência cultural, mas analisada pela ótica da dominação cultural, a história da arte brasileira torna-se ambígua. Se a política oficial para a cultura registra em nossa história alguns governantes como grandes incentivadores e financiadores das artes, a política aqui aplicada, inclusive a cultural, também é responsável pela imposição de uma identidade única, hegemônica, dominadora e opressora.

Então, a história da arte brasileira pode ser entendida como fruto da tensão pelo embate entre a manutenção de identidades culturais diversificadas, frente à hegemonia da herança da modernidade europeia, ou como ocorre na contemporaneidade, com a expansão da sociedade de consumo norte-americana no mundo neoliberal do mercado globalizado, em constante conflito com identidades dos povos dominados, escravizados ou imigrantes ${ }^{10}$.

O Brasil, não possuindo meios de produção, está sujeito à imposição de interesses dos países industrializados, e suas corporações econômicas transnacionais, inclusive no meio artístico. Na crítica "Arte e burocracia", de 1967, Mário Pedrosa diz que o "Brasil é assim, o único país do mundo que reconhece duas espécies de arte, 
uma 'acadêmica' ou 'clássica' e outra moderna" (PEDROSA, 1986, p. 104). Sua crítica propõe a reflexão sobre a confusão na prática artística provocada a partir do duplo investimento da política cultural brasileira que, nos últimos anos da década de 1960, concedia prêmios de viagens e bolsas para o exterior em dois salões de arte distintos e divergentes, mas que permitia aos artistas concorrerem em ambos ${ }^{11}$. Talvez porque nesse período fosse necessário responder com investimentos à produção "acadêmica", para a elite que sustentava a política interna, ao mesmo tempo em que o país deveria parecer "moderno" para as conexões internacionais, mas, ainda assim, discriminatório a produções artísticas que não se enquadrem em suas regras. O próprio Pedrosa afirma que os "artistas jovens (não apenas de idade) e revolucionários dos nossos dias estão marginalizados, conservados bem a distância dela [a arte], enquanto burocratas, confinados no seu isolamento, tratam de montar ali uma arte oficial, a seu gosto e pequena dimensão", e com isso especula sobre os interesses oficiais que classifica como "fora do compasso da atualidade, indiferente ou estranho ao que se faz hoje no Brasil de mais arriscado, de mais vivo e de mais... brasileiro"

Em meados da década de 1980 a função de "montar ali uma arte oficial" e indiferente ao que se produz de "mais vivo e de mais... brasileiro", migra do aparato estatal para outros os agentes, desta vez ligados ao mercado, que criam, também isoladamente, as novas regras para a arte brasileira. São agora os jornalistas e dirigentes de instituições culturais no Rio de Janeiro e São Paulo $^{12}$ quem investem na inserção de artistas brasileiros na tendência do mercado internacional chamado de Transvanguarda ${ }^{13}$, ou o retorno à pintura ${ }^{14}$, investimentos que resultam na exposição "Como vai você geração 80", no Parque Lage, Rio de Janeiro ${ }^{15}$. Mas Ricardo Basbaum esclarece que o corpo teórico formulado por Bonito Oliva, crítico italiano criador da transvanguarda, foi gerado a partir da produção de seu país e, devido ao seu amplo e rápido destaque, foi estendido a outras tendências internacionais da nova pintura (BASBAUM, 1988).

Em outras palavras, novamente o Brasil absorve tendências que Ihe são estranhas através da invenção intencional de uma situação que the aproxima da produção internacional dominada pelo mercado. A história da arte brasileira absorveu facilmente os preceitos ditados por Oliva e relegou ao esquecimento parte da produção "mais viva e (talvez) mais... brasileira" de toda a década. Marcia X, artista performática atuante na década de $1980^{16}$, disse que o problema é a incompreensão que existe no meio das artes plásticas, o descrédito que existe no Brasil em relação à performance, à arte política das minorias e que "é preciso lembrar que a geração 80 não produziu somente pintores. É que junto com os pintores o mercado de arte se fortaleceu, e fez surgir essa versão oficial da década" (MÁRCIA X, 2001) ${ }^{17}$.

Essa prática invencionista de regras, adotada pelos agentes das instituições culturais no Brasil, é implantada pela monarquia absolutista portuguesa e permanece na contemporaneidade, como se fosse um DNA que passa como herança do Estado para a sociedade, ou do financiamento estatal para o mercado - através do desmanche dos serviços públicos, desde o governo Collor de Mello, e da criação das Leis de incentivos fiscais que afastam a arte oficial do gosto e dos interesses do governante para jogá-la no seio do mercado. A história da arte brasileira relacionada às políticas culturais oficiais é a história do controle da produção, manipulação e circulação de bens simbólicos que visam a manutenção do poder sob o domínio político e cultural de uma elite conectada com interesses internacionais, que oficializa a arte que Ihe interessa e marginaliza qualquer tentativa de diferença.

Talvez o melhor exemplo dessa prática tenha sido a política adotada pela ditadura militar, depois do golpe de1964. Se por um lado o governo militar implanta a censura e a repressão à produção ideologicamente contrária ou crítica ao regime opressor, por outro foi o regime militar um grande financiador da arte brasileira. É nesse período que é criado - como já havia acontecido na ditadura anterior, a de Vargas - o aparato institucional, e a dotação orçamentária, que até hoje dita as regras da política cultural no Brasil, instituições como a FUNARTE, EMBRAFILME, Conselho Federal de Cultura, Instituto Nacional do Cinema, Pró-Memória, que, ainda sobreviventes ou remodeladas em outras siglas (juntamente com outras entidades oficiais criadas posteriormente), também permanecem na estrutura do Estado brasileiro. 
Se não é possível afirmar que os governantes da ditadura militar eram intelectuais preocupados em criar incentivos estatais para a produção artística, podemos especular que a criação desse aparato visava a utilização da produção de bens simbólicos para a legitimação do poder constituído. No discurso proferido pelo presidente Médici ${ }^{18}$ sobre a economia brasileira, no início de seu governo, ele afirmou ser muito simples a política econômica dos militares, resumindo tal pensamento na frase "os ricos devem ficar mais ricos para que, por sua vez, os pobres possam ficar menos pobres" (Departamento de estudos MB-75, p. 121 apud ORTIZ, 2001). É possível transpor esse pensamento para a política cultural da ditadura militar, aliás, para uma analogia mais razoável, temos no Manual Básico da Escola Superior de Guerra as diretrizes do tratamento dado aos meios de comunicação, ditando que quando estes forem "bem utilizados pelas elites constituir-se-ão em fator muito importante para o aprimoramento da Expressão Política; [mas quando] utilizados tendenciosamente podem gerar e incrementar inconformismo"19. Renato Ortiz diz que, para a cultura brasileira, a Lei de Segurança Nacional não detinha apenas o poder de repressão, mas interessava-se no desenvolvimento de uma determinada produção cultural submetida à razão do Estado, reconhecendo as relações de poder na produção cultural e entendendo a produção cultural como benéfica quando circunscrita no poder autoritário (ORTIZ, 2001, p. 116).

A ditadura militar fortaleceu, economicamente, a elite brasileira e ampliou o aparato institucional para controle ideológico dos meios de comunicação, e fez o mesmo com a produção cultural, transformando a produção artística em aparelho ideológico para manter o conformismo na população e, com isso, atingir sem muito esforço a manutenção do poder político.

Embora em ambiente hostil, artistas promoveram a resistência no seio das instituições culturais, como Artur Barrio que lançou em 1969 seu "manifesto contra as categorias de arte, contra os salões, contra as premiações, contra os júris, contra a crítica de arte (Manifesto Estética do Terceiro Mundo)". Contra, portanto, o sistema de arte e suas categorias, considerando-as uma imposição aos artistas latino-americanos, Barrio considerava sua situação econômica particular e dos artistas como um todo, quando dizia que "no sentido do uso cada vez maior de materiais considerados caros para nossa, minha realidade, num aspecto sócio-econômico de $3^{\circ}$ mundo (América Latina inclusive)", e, ainda, avaliando a imposição do uso de material ao dizer que "devido aos produtos industrializados não estarem ao nosso, meu, alcance, mas sob o poder de uma elite que eu contesto", lança sua proposta libertária, afirmando que "... a criação não pode estar condicionada, tem de ser livre". E acrescenta num manifesto escrito à mão distribuído na abertura do II Salão de Verão, em 1970, que os Salões estão "desestimulando novos valores e revelando o que já deixou de existir há muito tempo" (BARRIO, 2000).

Para ele a utilização de materiais caros e convencionais em trabalhos artísticos representava a continuidade dos "serviços" da arte ao gosto das elites, e em contraponto propõe materiais baratos e perecíveis para problematizar a questão econômica na arte. Fernando Cochiarale (2000, p. 17-18-19) explica que "a partir da crítica a essa realidade socioeconômica, étnico-política e estética Barrio deduz, com uma clareza rara na arte brasileira, o eixo fundamental de sua singular poética: conspirar contra o gosto das classes dominantes - no campo em que essas exercem seu poder cultural e operatório (poder assentado na crença da existência de um campo verdadeiro e puro da arte) - pela utilização de materiais precários e perecíveis, colhidos nos rejeitos de nossos trânsito no fluxo da vida". "Trouxas de carne", situação proposta por Artur Barrio para o evento "Do corpo à terra"20, é composta de pedaços de carne e ossos embrulhados em trouxas de pano espalhadas em espaços públicos, segue o princípio da transcendência da natureza cotidiana na qual se origina para a transposição de resquícios dessa vivência para o mundo da arte, onde, segundo Cochiarale (2000), eles perdem a conotação da propriedade física, visual e, por vezes, olfativa para assumir um estatuto crítico.

Para sua conspiração contra o gosto das elites, Barrio vai às ruas e intervém no cotidiano das cidades sem perguntar às pessoas se é isso que elas queriam, age a partir da sua percepção da realidade, inclusive a econômica, usando os rejeitos da sociedade de consumo para fazer seu trabalho em relação direta com a sociedade. 
Paulo Herkenhoff diz que a atitude de Barrio sustentou dois debates: o primeiro pela liberdade de expressão na ditadura e o segundo contra a desigualdade de expressão no capitalismo (HERKENHOFF, 2000, p. 26).

A consciência dos efeitos da economia mundial na economia e na produção artística latino-americana, somado aos aspectos socioeconômicos dos artistas brasileiros, é o que impulsiona o manifesto de Barrio, uma declaração da existência de imposições econômicas externas à arte e ao contexto da arte brasileira, inclusive das indústrias de materiais, ele reconhece a interferência na crítica, nos juris, nas premiações, e nos salões que mantém a classificação e distinção das categorias das artes plásticas em pintura, escultura, desenho e gravura ${ }^{21}$; e a contestação política, reflexão crítica das relações de poder, ou mesmo proposições provocativas à reação e enfrentamento feitas direto ao público (como: 'lute', "go home" ou 'crie seu espaço de liberdade') impulsionam a experimentação poética dos artistas plásticos 22 , distanciam a produção brasileira da filiação à obra dos chamados 'mestres' consagrados pela história da arte universal ${ }^{23}$; e, assim, os artistas, os críticos e o público criam condições para que o ambiente artístico brasileiro subverta o interdito oficial e funcione como espaço vivo de debate e circulação de ideias, bem como de resistência política e cultural ${ }^{24}$.

\section{A EMERGÊNCIA NEO-CABANA}

Na Amazônia a situação é agravada pelo isolamento histórico da região, o reflexo da segregação colonial e imperial também atinge a arte, que importada para o deleite da elite é negada à maioria da população. João de Jesus Paes Loureiro afirma que do ponto de vista oficial da classe dominante sobre a cultura amazônica, e "refletindo a separação qualitativa entre o alto e o baixo, [a visão oficial] tem entendido rigidamente como alto a produção alienígena e, como baixo, a produção local, regional" (LOUREIRO, 1985). E explica que no período da borracha, ápice na economia regional, consagrou-se esse modelo que legitima o 'importado' como boa arte, relegando a produção local à sua própria sorte na luta por sobrevivência e afirmação. Esse entendimento chega aos anos de 1980 como o que
Paes Loureiro chama de 'história trágica de uma queda', que instituiu a marca da elite em depressão psicossocial, a história de uma tristeza generalizada pela perda do refinamento artístico que o declínio econômico trouxe como consequência.

Olhando de uma outra perspectiva, Osmar Pinheiro Junior afirma que o isolamento cultural da região em relação à produção artística brasileira, ou mesmo de outro país, criou "formas agudas de esquizofrenia cultural", pois na Amazônia "discutia-se questões de arte, sem obras, e caminhos sem referenciais, movimentos de arte sem cronologia ou seja, sem história" [sic], resultado da "prática de uma elite sequiosa de diferenciação cultural, [que] determinou uma forma de estagnação cujas consequências se fazem sentir ainda hoje". Para ele, a história da arte amazônica é culturalmente dependente de modelos externos, uma "sucessão de episódios isolados sem nenhuma organicidade" (PINHEIRO JR, 1985).

Osmar Pinheiro percebe nas coloridas pinturas de fachadas de casas, de embarcações, e em toda a produção de cultura na mestiçagem amazônica, a revelação de "condições particulares de uma outra ordem, onde não existe mercado de arte, onde o suporte da obra é a casa, o barco, o boteco, o papagaio, o brinquedo. Onde o artista são todos [...]. Onde arte e trabalho são parte de um mesmo movimento cuja razão é o afeto; que quatro séculos de violência colonizadora não foram capazes de destruir" (PINHEIRO JR, 1985). Paes Loureiro acrescenta, ainda, que essa produção subalterna é nossa contracultura, forma de resistência. É uma inversão na ótica da exploração, já que propõe a apropriação da herança cultural do colonizador para que se 'capture o capturante', e a região passe "a ser vista por dentro, como quem olha 'da região', e não como quem, mesmo de dentro, olha 'a região'" (LOUREIRO, 1985).

Em outras palavras, a segregação, que foi marca da origem colonial, ainda é percebida como um colonialismo interno há cerca de vinte anos atrás, tanto na política cultural do Brasil pós-ditadura militar, quanto na historiografia regional que legitima a versão da decadente elite local.

A possibilidade de resistência cultural se apresenta, senão na hipótese improvável de se tornar pura, ao menos na consideração das nossas relações com a natureza, ordem social 
e seus símbolos, que nos livra da mordaça dos cânones modernistas e nos alforria daquilo que nada acrescenta. E, assim, fazer soar a voz dos marginalizados no processo controlador de desenvolvimento regional. No nosso caso, no Grupo Urucum, entendo como um voltar-se pra si que não exclua um expandir-nos para os outros, que entendo como questionamento à autonomia moderna na instituição arte, percebida pela população como pertencente a um espaço separado e sem comunicação com outras esferas da vida, o que afasta a arte da sociedade para outro mundo onde a arte quer bastar-se em si mesma, essa separação a torna entorpecente e inofensiva. Aliado a ações que visem a consciência de existência e possa contribuir com a mobilidade social de capacidade transformadora.

Macapá, capital do Estado do Amapá, ainda hoje não possui espaços físicos que Ihe possa garantir um circuito de arte consolidado, apenas a galeria do SESC funciona regularmente e não há nenhum museu de arte; tem, ainda, uma escola de artes plásticas que funciona com cursos livres de ensino de técnicas; outra de música, e o curso de licenciatura em artes visuais da Universidade Federal do Amapá ${ }^{25}$. Situa-se, geograficamente, na Amazônia oriental, na foz do rio Amazonas, sendo conhecida por ser a única cidade brasileira cortada pela linha do Equador.

Urucum é palavra da linguagem indígena, uru'ku, 'vermelho', cuja polpa é usada como pigmento, e também evoca rituais dos povos indígenas, ditos primitivos, porque com ela se faz sulcos cor de sangue na pele e que é, ao mesmo tempo, identidade e diferença de quem pinta o corpo: para a guerra ou para a festa.

Quando em 1996 eu fui para o Amapá, o Grupo Urucum já existia, minha integração ao grupo acontece em 2001, quando retornava novamente para a cidade, depois de passar uma temporada no Rio de Janeiro. Participei de alguns debates no atelier de trabalho do grupo, onde discutimos sobre a política cultural do Amapá, as questões propostas na produção individual dos membros do grupo, inclusive na minha, e sobre a realidade da cidade de Macapá ${ }^{26}$. O grupo, que havia se formado como alternativa solidária para realização de propostas individuais, na perspectiva de formação de mercado, experimentava a criação coletiva em esculturas/monumentos, marcos comemorativos em Macapá e Kourou, na Guiana ${ }^{27}$, e planejava uma ação para a 'esquina das andorinhas' 28 , no centro de Macapá.

Da realidade local, e do debate público sobre as consequências do fenômeno natural da migração das andorinhas que param na cidade durante sua rota migratória, e afetam a vida urbana, fizemos uma ação: ocupamos a 'esquina das andorinhas', cruzamento das avenidas Padre Júlio Maria Lombaerd e Cândido Mendes, espalhando penicos coloridos pelos quatro cantos das duas vias. Éramos "Os catadores de orvalho esperando a felicidade chegar" (título do trabalho). Chegamos vestindo uniforme preto com touca de natação, meias brancas e óculos de descanso, no mesmo momento que iniciou o "balé" do pouso das andorinhas na rede elétrica, passamos a noite toda velando o descanso dos pássaros e movimentando cores na esquina, andando, dançando e mudando de posição para procurar o melhor lugar para acertar no alvo do penico a mira dos projeteis fisiológicos das andorinhas, a merda que gera o debate entre os ambientalistas e o poder público e tanto incomoda o comércio e agências bancárias localizadas na esquina.

Nossa presença e a falta de reconhecimento de objetivos práticos para aquela movimentação em torno das andorinhas resultou em interpretações diversas no público passante, e tensões que por pouco não resultaram em conflito. Tensão com o poder político-econômico, ao ser interpretado como ação da administração pública ou do comércio para afastar - ou matar - as andorinhas e seus dejetos da área comercial ${ }^{29}$. Poética e política confundem-se na ação que provoca a reação popular ao poder constituído, e que quer transformar merda em orvalho e proporcionar o encontro da felicidade, a felicidade de presenciar a revoada das andorinhas, de parar na esquina para ver o que acontece, de reconhecer o diferente, de movimentar objetos coloridos pelos prédios cinzentos. Criamos um evento, uma tragédia - no sentido sociológico de quebra da rotina que permitiu o deslocamento da percepção de alguns dos próprios habitantes sobre a realidade de Macapá.

Mário Pedrosa (1986, p. 87) identifica a integração da arte na vida social como o problema em 
questão, e a integração do homem ao seu trabalho e às relações sociais implícitas nesse processo, com isso cria a possibilidade da arte se afastar do circuito oficial -dos seus agentes e da lógica do mercado -, para integrar-se na coletividade, dissolvendo o artista e a autoria da obra de arte na sociedade. Buscamos essa situação de inserção no corpo social, em outras palavras, podemos até veicular os registros dos trabalhos em instituições culturais, mas as ações desenvolvidas pelo grupo visam atingir diretamente a população e suas questões, e assim colocamos nosso trabalho no debate [embate] das tensões da natureza do lugar em que vivemos.

A população e seus anseios é a questão do "Mensagens vazias" ${ }^{30}$, realizado a partir do convite para uma intervenção na sala de experimentação da Casa das Onze Janelas ${ }^{31}$, o grupo aceitou fazer um trabalho para o Museu, desde que não fosse uma obra, mas os registros de uma proposta de ação relacionada à vida amazônica, e para realização nas duas capitais da foz do rio Amazonas ${ }^{32}$.

Trabalhamos com a ideia de evento, e mais especificamente da festa, mas na fissura temporal, na passagem... onde não podemos definir exatamente em que ano estamos. Nos instalados próximo à Fortaleza de São José de Macapá, durante a passagem de ano, de 2002 para 2003, abordávamos as pessoas pedindo que escrevessem seus desejos em pedaços de papel para colocar esses bilhetes em garrafões que foram lançados ao rio Amazonas. Integrada a essa ação criamos uma instalação/intervenção com garrafas vazias na área de Santa Inês durante a maré seca, também levada pelo movimento de maré ${ }^{33}$.

O real e a representação são parte do jogo proposto pelo grupo. Se a arte sintetiza emoções através de sua representação, convocávamos todos a exporem suas emoções ao escreverem seus desejos, e com isso relembrarem os motivos que os fazem desejar. 0 sentimento não é mais escamoteado, está todo aqui no momento do agora! Dessa forma não emolduramos representações, mas engarrafamos as emoções da população em um escambo onde a arte está no campo da vida - não se trata de trazer a vida para a arte, mas confundi-las - e ao se completarem caminham para o domínio do real e não mais da representação ${ }^{34}$. A postura é inversa à garrafa do gênio que surge da fumaça para realizar seus desejos, aqui você os coloca nas garrafas, as garrafas vão para o rio e é você quem pode realizá-los.

Richard Huelsenbeck, no manifesto Dada de 1918 [sic], apontava para a necessidade de uma prática cultural de caráter libertária no seio da sociedade, para ele "a arte, para sua execução e desenvolvimento, depende do tempo no qual vive", e que a arte maior será aquela que apresentar conteúdos conscientes dos múltiplos problemas de seu tempo, "aquela que se fará sentir como sendo sacudida pelas explosões da semana precedente, aquela que tenta se recompor depois das vacilações da noite anterior", pois para ele os artistas são um produto de sua época, e "os melhores e mais insólitos artistas são aqueles que a qualquer momento arrancam pedaços do próprio corpo, do caos da catarata da vida e os recompõe".

Na experiência coletiva a arte se aproxima das questões cotidianas daqueles que se envolvem no trabalho, e por isso mesmo tende a atingir diretamente a vida dos membros da comunidade e tornar-se reflexo da sociedade em contrapartida da ideia de arte como produto de gênios criadores que vivem em um mundo inalcançável aos 'seres comuns'. A concepção é da arte com função social, como pregava Huelsenbeck, em contrapartida da doutrina da arte pela arte, que Benjamin identifica como antecessora da 'teologia negativa' da arte sob a forma de arte pura, que rejeita toda função social e determinação objetiva (BENJAMIN, 1994, p. 171), e ele mesmo já havia dito, em relação às práticas dadaístas, que "o menor fragmento autêntico da vida diária diz mais do que a (representação pela) pintura" (/d., p. 128).

À formulação de exigências revolucionárias na política artística, que Benjamin propõe na introdução de 'A obra de arte na época de sua reprodutibilidade técnica' (/d., p. 166), e que já estavam no manifesto dadaísta, encontra ressonância em Jean-Jacques Lebel, que aponta com a possibilidade de falar de arte e política em termos dionisíacos. Sem importar-se se é uma formulação legítima, ele conceitua anarcodadaismo como 'um sentimento de alegria que faz dançar'. Para ele é necessário dadaizar "o discurso e a ação revolucionários, conferindo-Ihes um corpo" (LEBEL, 1998). Lebel reclama do 'reino da 
ordem mortífera', com que chama a calma absoluta, a glaciação, provocada pela submissão resignada obtida por narcose medial, e aponta o incentivo musical, poético, artístico e filosófico à dança (no sentido anarco-dadaista) como alternativa à imobilidade social, "de modo que essa [sociedade] possa recomeçar a dançar os próprios desejos, em vez de nega-los ou militariza-los" (/d.).

Mesmo que a história da arte, o manifesto dadaísta ou os textos de Lebel sejam desconhecidos da maioria dos integrantes do Grupo Urucum, o debate público, a mobilidade social e outros preceitos artísticos estão presentes nas ações do grupo, bem como a intensão de agir no seio da sociedade e de que nossos trabalhos tenham ressonância social. O que me faz acreditar que nossa produção é uma produção de resistência política e cultural.

\section{NOTAS}

1. Texto escrito em 2005, conforme o autor, "não terminado e não publicado". Enviado em 14 de fevereiro de 2012, como opção de publicação para o livro "Amazônia, lugar da experiência processos artísticos da região Norte dentro da Coleção Amazoniana de Arte da UFPA (Belém: Edufpa, 2013), organizado pelo artista, curador e professor Orlando Maneschy, juntamente com o texto "Güera". Este último, pela escolha editorial, fora publicado no referido livro, deixando acordada a publicação do presente ensaio em outro momento oportuno. Acreditamos que o Dossiê Amazônia da Revista Arteriais seja ambiente significativo para a presença dos posicionamentos e atuações de Arthur Leandro sobre o sistema da arte brasileira/ amazônica, além de contribuir para a disseminação do seu legado. Razão pela qual os editores da revista compreenderam a importância deste ensaio na presente coletânea sobre a arte na Amazônia.

2. Me interessa a análise sobre a produção coletiva, mesmo sabendo da pratica de outras estratégias de agenciamento dos integrantes do grupo.

3. E também nas duas participações do Grupo no "Dia do Nada", em 2003 e 2004, com os trabalhos "Estamos em pleno rio-mar... Doido espaço... Estamos em pleno rio-mar... Dois infinito..."; e "Farofa de ovo ou Tudo o que há no rio, nada!", respectivamente.
4. A convite para intervenção na Casa das 11 janelas - Museu de Arte Contemporânea do Pará, o trabalho foi pensado e realizado para uma intervenção, para a qual fomos convidados e que nunca aconteceu.

5. Proposição para o projeto de intercambio INTERFACES, da EBA/UFRJ com o Reseau L'age d'Or, o Grupo Urucum participa a partir da argumentação de que minha pesquisa para doutoramento naquela escola tratava da poética do coletivo do Urucum e não caberia uma proposição individual se meu trabalho era no Grupo.

6. Para mim é difícil especificar qual é a pessoa que fala, a do singular ou a do plural, e para usar a alegoria poética: me imagino como um peixe na pirapora $\gg \gg$ pira=peixe, pora=salto $\gg>$. Como quem salta para encontrar sua singularidade fora do coletivo (o plural) e novamente mergulhar na massa social liquida tentando analisar aquilo que percebeu tanto na convivência coletiva quanto na singularidade do salto que realizou na tentativa de vencer a corrente do rio, na contracorrente.

7. Entre 1808 e 1810 o governo lusitano promove a abertura dos portos às nações amigas; revoga as proibições à manufatura; cria instituições como escolas de medicina na Bahia e Rio de Janeiro, academias militares e intendência de polícia, entre outras.

\section{Que passa a funcionar a partir de 1826.}

9. Marx e Engels, no Manifesto do Partido Comunista, apontavam, alguns anos depois, a necessidade de expansão de mercados para a produção industrial, que revoluciona constantemente a tecnologia de seus instrumentos de produção e arremessa todas as nações para a torrente da civilização, dizem ainda que, para a inserção no seio da chamada civilização, a burguesia obriga "todas as nações [...] a adotarem o [seu] modo de produção", imposição que identificam como o projeto de reprodução das relações burguesas por toda parte, para assim conquistar a terra inteira" (MARX; ENGELS, 2002, p. 28-32). O Manifesto do Partido Comunista se refere apenas aos meios de produção de bens e de capital, mas facilmente podemos projetar esse universo para a produção artística e cultural, pois, para Antonio Gramsci, o conceito de hegemonia 
caracteriza a liderança cultural que garante a dominação, considerando que os mundos imaginários funcionam como matéria espiritual para se alcançar um consenso reordenador das relações sociais, consequentemente orientado para a transformação, ele explica que as formas históricas da hegemonia nem sempre são as mesmas e variam conforme a natureza das forças sociais que a exercem. Sérgio Buarque de Holanda exemplifica o caso brasileiro ao dizer que a tentativa de implantação da cultura europeia no extenso território e em condições naturais hostis está nas raízes do Brasil, e que somos desterrados na nossa terra, e, ainda, pergunta se podemos representar as formas de convívio, instituições e ideias das quais acreditamos que somos herdeiros.

10. O manifesto do partido comunista prevê a globalização do mercado para a manutenção do sistema capitalista, que traz em si as relações de domínio, subordinação e dependência, pois os instrumentos de produção de bens e o conhecimento tecnológico que impulsiona o progresso, inicialmente posse exclusiva da burguesia, que Marx e Engels criticavam, e que permanecem sob o domínio de uma elite econômica agora representada pelas corporações transnacionais na economia neoliberal, cujos interesses de mercado passam a interferir em todas as instancias de decisão, inclusive nas políticas nacionais, em escala mundial.

11. O exercício do sistema já criou mesmo a aberração. Como? Permitindo a um participante do Salão acadêmico [...] no dia seguinte apresentar-se ao salão "moderno" e ganhar neste o grande prêmio de viagem cobiçado. Assim reconhece-se oficialmente a possibilidade de um sujeito, já consagrado como artista "acadêmico" ou "clássico" ser meses depois consagrado como artista "moderno" (PEDROSA, 1986, p. 104).

12. Em São Paulo, Sheila Leirner defende uma geração feliz no Estado de São Paulo. No Rio de Janeiro, Roberto Pontual, autor do opúsculo Explode Geração!, encomendado pelo galerista Thomas Cohn, apresentava os jovens artistas no contexto do pós-modernismo internacional e da abertura política brasileira, situando-os como opositores do "isolacionismo e do autoritarismo conceitual da geração precedente"(1984). No O
Globo, Frederico Morais dava sequência a uma série de artigos, que vinha escrevendo desde 1982, difundindo as teorias do crítico italiano Achille Bonito Oliva, mentor da transvanguarda e interlocutor do neoconservadorismo artístico no cenário internacional.

13. As exposições Europa 79, Bienal de Veneza, Documenta 7, e Bienal de Paris (1) difundem a transvanguarda e dão impulso ao mercado internacional de arte nos fins dos anos 70 e início dos anos 80 .

14. O Retorno à Pintura enquanto "última tendência da arte contemporânea" - tal como na ocasião chegou a ser festejado pela crítica - representou mais do que uma confissão do mercado quanto a sua limitação para continuar absorvendo as transformações da linguagem da arte contemporânea que havia décadas vinham sendo promovidas por sucessivos movimentos vanguardistas. Em verdade, o Retorno à Pintura foi um movimento artístico e teórico representativo de diversos grupos de artistas, críticos e acadêmicos defensores de uma cultura pós-moderna opositiva à cultura do chamado alto modernismo (...) De fato, analisando as edições da Bienal de São Paulo de 1983 e de 1985, além da mostra "Como vai você, Geração 80?", realizada no Rio de Janeiro em 1984, chega-se facilmente à constatação de que esses eventos não apenas introduziram o fenômeno do Retorno à Pintura e sua estética anti-historicista como símbolos da "chegada" do pós-modernismo no Brasil, como também serviram para propagar na órbita do mercado de arte e do mecenato institucional do país a "pirâmide da felicidade" em que havia se transformado mundialmente aquele fenômeno (REIS, 1998).

15. Participam da exposição: Antônio Dias, Cildo Meireles, Ivens Machado, Jorge Guinle, Leda Catunda, Leonilson, Roberto Magalhães, Sérgio Romagnolo, Tunga e Victor Arruda.

16. Uma entre tantos esquecidos pela história da arte oficial dos anos 80, como, apenas no contexto carioca: "Alex Hamburger", "Dupla especializada", "Grupo A Moreninha", "Aimberê Cesar" e outros.

17. X, Marcia. Entrevista datada de 2001. Disponível em: http://www.marciax.art.br/ mxText.asp?sMenu=5\&sText $=3$ 
18. CNN, Para além de cidadão Kane. Videodocumentário. Londres: CNN, 1992.

19. Como no conceito de Gramsci, o controle serve para obter a hegemonia, que leva à liderança, que garante a dominação cultural, que funciona como matéria espiritual para se alcançar um consenso (re)ordenador das relações sociais.

20. Realizado no Parque Municipal de Belo Horizonte, em abril de 1970. "O evento Do Corpo à Terra durou três dias, durante os quais foram realizadas ações, rituais e celebrações tais como a queima de animais vivos por Cildo Meireles, a explosão de granadas coloridas por Décio Noviello, o lançamento de 'trouxas ensanguentadas' por Barrio num ribeirão que corta a capital mineira, a queima de faixas de plástico com napalm por Luiz Alphonsus, trilhas de açúcar na terra por Hélio Oiticica ou o emprego de carimbos com frases de impacto por Teresa Simões. O crítico Francisco Bittencourt referiu-se a esse grupo de artistas como Geração Tranca-Ruas, e Frederico Morais, organizador do evento, no texto Contra a Arte Afluente: O Corpo É o Motor da Obra (Revista Vozes, 1970), afirmava: "O artista hoje é uma espécie de guerrilheiro" (MORAIS, 1991).

21. E que hoje podemos acrescentar a fotografia, o vídeo e demais meios eletrônicos absorvidos sob o novo termo de Artes Visuais.

22. Se não de todos, ao menos de parte qualitativa e quantitativamente relevante de artistas atuantes nesse período. Ações e trabalhos classificados como 'de resistência' foram realizados por artistas desde a implantação da ditadura militar brasileira, e da sua política cultural autoritária. Antônio Manuel faz, em 1968, "Imagens da violência", em referência direta às imagens de conflitos entre a sociedade civil e o governo militar, um ano antes Carlos Zilio havia exposto "Lute (Marmita)", uma marmita de alumínio, objeto do cotidiano de operários e outros trabalhadores assalariados, com um rosto anônimo em papier maché e coberta com um filme plástico com a inscrição: LUTE. "Do It Yourself: freedom Territiry" (1968) [Faça você mesmo: território de liberdade], de Antônio Dias, apresentada no Museu Nacional de Arte Moderna de Tokio, demarcações de espaços quadrados demarcados no chão com adesivos ou plotagem de um metro de comprimento, formando um retângulo de $6 \times 4$ m., nos dá várias possibilidades de significações, inclusive a de provocação ao público do museu. Para fora do circuito oficial da arte, mas nem por isso fora da crítica ao sistema, Cildo Meireles veicula seus trabalhos em meios cotidianos e oficiais de uso popular. Assim são suas "Inserções em circuitos ideológicos" - uma operação provocadora da ordem pública, interferencia nas estruturas que simbolizam e garantem o poder estabelecido. Em 1970 realiza o "Projeto coca-cola" - garrafas de coca-cola com a inscrição "yankees go home", em branco, frase que somente era vista quando as garrafas estavam cheias do refrigerante símbolo do poder do Imperialismo norte-americano. A mesma garrafa que difundia o império capitalista divulgava - como uma imprensa oculta - a mensagem anti-imperialista, da mesma forma a mensagem "Quem matou Herzog?" carimbada em notas de cruzeiro de baixo valor agia contra a violação dos direitos individuais na ditadura. Na mesma direção provocativa, Carlos Vergara apresenta a obra "Fome" (1972) na 'EX-Posição', com as letras da palavra FOME escritas com grãos de feijão sobre algodão umedecido. Os grãos germinam e as letras se misturam, entrelaçam e perdem a forma original não podendo mais haver a leitura da palavra, referência direta ao slogan dos governos militares "em se plantando, tudo da".

23. Através do estudo dos códigos de representação de artistas consagrados para depois atualiza-los, adapta-los à temáticas locais, subverte-los, contesta-los etc., procedimento moderno de produzir arte referendada na própria (história da) arte - arte pela arte.

\section{Tanto quanto nas artes cênicas e na música.}

25. Criado em 1991 como licenciatura plena em Educação Artística do Núcleo de Educação de Macapá - NEM/UFPA.

26. Como o grupo é formado pelas pessoas que dividem o espaço de trabalho naquele local, e eu não ocupei o espaço físico do Urucum para o desenvolvimento das minhas propostas individuais, a mim passou despercebido o momento em que fui reconhecido como parte integrante da comunidade.

27. Encomendas oficiais por parte do governo estadual para esculpir totens, na realidade marcos-monumento, com elementos da cultura 
amazônica na estação rodoviária de Macapá em 1999, e em 2000 para um entroncamento rodoviário entre Kourou e Cayenne, que é o símbolo da integração entre o Amapá e a Guiana, Brasil e França. Existe um outro inacabado em Laranjal do Jarí, de 2002-03.

28. Cruzamento das avenidas Padre Julio Maria Lombaerd e Cândido Mendes, na área comercial de Macapá. É uma espécie de parada de descanso na rota migratória das andorinhas, fenômeno natural que gera um debate constante na cidade, inclusive de saúde pública, por deixar resíduos fecais nas vias públicas.

29. Raoul Vaneigem trata da familiaridade entre a vida cotidiana e aquilo que a destrói, e diz que existe um momento definido historicamente, pela força e fraqueza do poder, de superação nessa relação, e que a superação está na realização do projeto de liberdade individual, construído pela subjetividade e espontaneidade, o modo de ser da criatividade, que é um estado de subjetividade. Para ele a poesia é a organização da espontaneidade criadora que a difunde no mundo e gera novas realidades, gesto revolucionário por excelência. VANEIGEM (2002).

30. Concebido em conjunto com a poeta Josete Lassance.

31. Museu de Arte Contemporânea do Pará. O convite partiu da curadora Rosely Nakagawa, consultora do Museu.

32. Não sabemos os motivos pelos quais esses registros nunca foram expostos na sala para o qual foi concebido a convite do próprio museu.

33. Aqueles que aceitavam a sedução do grupo terminavam por compartilhar seus desejos com outros desconhecidos, misturando pedidos, vontades e desejos íntimos aos desejos também secretos de todos os outros. Independente de credos, origem social ou étnica, os transeuntes transformaram os garrafões numa grande integração dos anseios do povo de Macapá.

34. Claude Lévi-Strauss observa na arte dos Caduceus uma operação diferenciada dos estudos artísticos europeus, de percepção e representação (inclusive a mimética) do real, os caduceus, como a maioria dos povos autóctones, pinta, ou grava em tatuagens, sobre o corpo em carne e osso diretamente no real. Da observação straussiana
Mario Pedrosa reflete sobre a diferença de atitude entre os povos (ditos) primitivos e a concepção de arte europeia: a tradição artística ocidental tende a representação do real, enquanto a manifestação e manipulação simbólica das sociedades tribais intervém no corpo, no real (PEDROSA, 1986, p. 222).

\section{REFERÊNCIAS}

BARRIO, Artur. Manifesto da estética do terceiro mundo. In: LENZ, André \& BOUSSO, Daniela (Org.). Artur Barrio, a metáfora dos fluxos: 1968/ 2000. Rio de Janeiro, Salvador, São Paulo: MAM-RJ, MAM-BA, Paço das artes, 2000.

BASBAUM, Ricardo. Pintura dos anos 80: Algumas observações críticas. Gávea Revista do Curso de Especialização em História da Arte e Arquitetura no Brasil, n.6. Rio de Janeiro. PUC-RJ, 1988.

BARROS, Aidil J.P. \& LEHFELD, Neide A. de S. Fundamentos da metodologia. São Paulo: McGraw-Hill: 1996.

BENJAMIN, Walter. Obras escolhidas: magia e técnica, arte e política, Vol. I. São Paulo: Brasiliense. 1994.

CANCLINI, Nestor Garcia. Culturas Hibridas: estratégias para entrar y salyr de la modernidad. Buenos Aires, Barcelona, Mexico: Paidos. 2001.

CNN, Para além de cidadão Kane. Vídeodocumentário. Londres: CNN, 1992.

COCHIARALE, Fernando. Arte em trânsito: do objeto ao sujeito. In LENZ, André \& BOUSSO, Daniela (Org.). Artur Barrio, a metáfora dos fluxos: 1968/2000. Rio de Janeiro, Salvador, São Paulo: MAM-RJ, MAM-BA, Paço das artes. 2000.

FREIRE, Paulo. Cartas à Guiné Bissau. Rio de Janeiro: Paz e Terra: 1978.

HERKENHOFF, Paulo Barrio - liberdade, igualdade e ira. In: LENZ, André \& BOUSSO, Daniela (Org.). Artur Barrio, a metáfora dos fluxos: 1968/ 2000. Rio de Janeiro, Salvador, São Paulo: MAMRJ, MAM-BA, Paço das artes. 2000.

LEBEL, Jean-Jacques. Dadaizar a sociedade. In: Revista Libertária. São Paulo: Imaginário, janeiro de 1998. 
MARX, Karl \& ENGELS, Friedrich. Manifesto do partido comunista. Porto Alegre: L \& PM. 2002.

MORAIS, Frederico. Panorama das artes plásticas séculos XIX e XX. São Paulo: Instituto Cultural Itaú, 1991.

ORTIZ, Renato. A moderna tradição brasileira. São Paulo: Brasiliense, 2001.

PAES LOUREIRO, João de Jesus. Por uma fala amazônica. In: FUNARTE. As artes visuais na Amazônia, reflexões sobre uma visualidade regional. Rio de Janeiro/Belém: FUNARTE/ SEMEC. 1985.

PEDROSA, Mario. Mundo, homem, arte em crise. São Paulo: Perspectiva, 1986.

PINHEIRO JR., Osmar A visualidade amazônica. In: FUNARTE. As artes visuais na Amazônia, reflexões sobre uma visualidade regional. Rio de Janeiro/Belém: FUNARTE/SEMEC, 1985.

REIS, Ronaldo Rosas. Conformismo pós-moderno e nostalgia moderna. In: Revista Cyberlegenda, n.1, Niteroi: UFF, 1998.

VANEIGEM, Raoul. A arte de viver para as novas gerações. São Paulo: Conrad. 2002.

X, Marcia. Entrevista. 2001. Fonte: http://www. marciax.art.br/mxText.asp?sMenu $=5 \&$ sText $=3$

\section{SOBRE O AUTOR}

Arthur Leandro (1967-2018) é graduado em Arquitetura e Urbanismo pela Universidade Federal do Pará (1992), Mestrado em Artes Visuais pela Universidade Federal do Rio de Janeiro (2000). Foi professor assistente da Universidade Federal do Pará; colaborador do Instituto Nangetu de Tradição Afro-religiosa e Desenvolvimento Social; coordenador da REATA - Rede Amazônica de Tradições de Matriz Africana. Táta Kisikar'Ngomba ria Mansu Nangetu foi artista colaborador da Federação Paraense de Cineclubes; titular do conselho de beneméritos - ACESB Embaixada de Samba do Império Pedreirense; Conselheiro Titular no Conselho Municipal de Política Cultural de Belém; Conselheiro Suplente no Conselho Nacional de Promoção da Igualdade Racial/CNPIR - Ministério das Mulheres, Igualdade Racial e Direitos Humanos; Conselheiro Titular no Colegiado de Culturas Afro-brasileiras do Ministério da Cultura; Conselheiro Titular representante das Culturas Afro-brasileiras no Conselho Nacional de Política Cultural do Ministério da Cultura/ CNPC-MINC de 2012 a 2015. Com experiência na área de Artes, com ênfase em CULTURA, atuou principalmente nos seguintes temas: culturas afro-brasileiras, arte contemporânea, linguagens visuais, vivências, vídeo e intervenção urbana. 